\title{
Clinical supervision for novice millennial nurses in the perinatal setting: The need for generational sensitivity
}

\author{
Jo Watson ${ }^{1,2}$, G. J. Macdonald ${ }^{2}$, Donna Brown ${ }^{1,2}$ \\ ${ }^{1}$ Sunnybrook Health Sciences Centre, Toronto, Canada \\ ${ }^{2}$ Lawrence S Bloomberg Faculty of Nursing, University of Toronto, Toronto, Canada \\ Email: jo.watson@sunnybrook.ca
}

Received 18 May 2013; revised 19 June 2013; accepted 10 July 2013

Copyright (C) 2013 Jo Watson et al. This is an open access article distributed under the Creative Commons Attribution License, which permits unrestricted use, distribution, and reproduction in any medium, provided the original work is properly cited.

\begin{abstract}
This paper reports on a qualitative research study that examined the experience of expert and novice nurses participating in a new, reflective program of "clinical supervision", intending to facilitate the transition of new graduate nurses into the workforce. Three patterns emerged during the constructivist inquiry: readiness to reflect, valuing of clinical supervision, and sustainability of the clinical supervision model. The researchers suggest generational sensitivity as a key perspective to consider when developing engaging workplace strategies for millennial nurses. The article offers recommendations for the implementation of clinical supervision and would be of interest to nurse leaders in a clinical setting.
\end{abstract}

Keywords: New Graduate Nurses; Clinical Supervision; Generational Sensitivity; Constructivist Inquiry

\section{INTRODUCTION}

Novice nurses face real challenges when entering the workplace. They are particularly vulnerable to high levels of burnout, increased levels of depersonalization, and lower levels of personal accomplishment than more experienced nurses [1,2]. Difficulties for these new members of the profession lead to rising attrition rates and possible marginalization [3,4]. New programs and approaches are needed that engage novice nurses in the profession by helping them transition into the workplace. During this transition, novice nurses could benefit from a system of support that fosters reflective practice.

\subsection{Review of the Literature}

Born between 1980 and 2000, most current graduates belong to Generation $\mathrm{Y}$ and are known as millennials [5]. Millennial nurses expect quick access to their leaders and want prompt, frequent feedback [6]. Unlike previous generations, millennials are drawn to work that they perceive to be meaningful and to work environments that support a work-life balance [7,8]. Having grown up learning and working in groups, they favour teamwork, collaboration, interdependence and networking [9].

The difficulties that new nursing graduates experience are well described in the literature [2,7]. Novice nurses find the first months of work the most difficult. They are acutely aware of missing their clinical instructor and may even contemplate leaving the profession [2]. New graduates have long been labeled as inadequately prepared to transition easily into the workplace [10]. This is not surprising since the new graduate's experience is recognized as a time of significant professional adjustment [7].

Recommendations have been made to develop workplace strategies focused on easing new graduates' transition into professional practice [3,7]. One potential support identified for new nurses is participation in the practice of clinical supervision (CS) following orientation. Clinical supervision, an approach used for decades in the United Kingdom, is a "formal process of professional support and learning, which enables practitioners to develop knowledge and competence and assume responsibility for their own practice" [1], previously cited in the London Department of Health 1993 [11]. This approach to supporting staff has been linked to the provision of quality care, role socialization, and acculturation [7].

A key element of clinical supervision is the involvement of experienced or expert nurses who provide support and guidance to novice nurses and promote reflective practice. Expert nurses work to create a safe environment, share their wisdom explicitly, facilitate reflection and provide effective feedback [12]. Novice nurses participating in clinical supervision are expected to identify key concerns in practice, remain open to 
feedback, and engage in reflection [12]. Clinical supervision takes place after a formal orientation has been successfully completed. It is not meant to be a type of preceptorship and does not include shared shifts or hands-on clinical support.

Suggested benefits of participating in clinical supervision include increased confidence, decreased isolation and burnout, increased feelings of support, decreased sick time, as well as improved listening, problem solving and coping skills [13-18]. The value of clinical supervision has been specifically highlighted for novice nurses in $[19,20]$. These benefits suggest clinical supervision is an ideal approach to foster the engagement of novice nurses in reflective professional practice. Yet, uptake of this initiative has been inconsistent and not all reports are positive. Concerns raised in the literature regarding clinical supervision include resistance, fear and suspicion, as well as the lack of organizational and policy support [21-25].

While there is no clear consensus on how clinical supervision is best implemented in clinical practice, the value of clinical supervision for novice nurses has been established [14]. Clinical supervision is an initiative worthy of consideration as a means of professional development for Canadian nurses and as a strategy to support novice nurses during their transition into the profession. There are no reports of clinical supervision being implemented in Canadian practice settings or, more specifically, evaluated in perinatal units.

\subsection{Study Introduction, Guiding Questions}

The purpose of this study was to explore the experience of novice and expert nurses during their participation in a program of clinical supervision, introduced into a Canadian, perinatal setting. The research question guiding the study was: What is the nature of the experience of novice nurses and expert nurses who participate in a program of clinical supervision during the first year of the novice nurses' clinical practice?

The goal of the CS program was to support and engage novice nurses during their transition into the profession in their first year of practice.The CS program was introduced in a letter sent out to novice nurses, who had completed their formal orientation. Novice nurses were asked to review written material and guidelines about CS before the meeting. Participants were paid for their time at their regular hourly rate. The letter also invited the nurses to a one-hour group session to introduce the research study.

The Clinical Supervision program consisted of three meetings, between paired novice/expert nurses. These meetings followed the formal orientation and were completed within the first year of the novice nurses' employment. Meetings were unstructured and allowed the novice nurses to reflect upon any successes, concerns or questions they may have had about their professional life. The initial meeting took place within three months of the end of orientation. Subsequent meetings between expert nurses and novice nurses were held within the next nine months. This meeting schedule resulted in novice/expert nurse dyads planning to meet a total of three times during their first year of practice.

Ten novice nurses were invited to participate in the study. These ten nurses were practising in the perinatal setting, had successfully completed their formal orientation program, and were beginning their mandated clinical supervision program. In this program, each novice nurse was paired with an expert nurse. Three expert nurses, who were providing individual clinical supervision to one or more of the cohort of ten novice nurses, were also invited to participate in the study. The three mid-career, expert nurses worked in advanced practice nursing roles in the perinatal setting.

Three novice nurses and the three expert nurses volunteered to participate in the study. The novice nurses were identified with the millennial age cohort while the expert nurses were identified with the baby boomer age cohort. The expert nurses did not know the identity or number of the novice nurses who were research participants. The novice nurses were not aware of the identity or number of expert nurses who participated in the research study.

\section{STUDY DESIGN AND METHODS}

Separate focus groups, one for novice nurses and one for expert nurses, took place after the program of clinical supervision was completed. Data was collected through two focus groups that provided the opportunity to explore the research question with the novice and expert nurses. Focus groups are a methodology particularly well suited for use with small groups of vulnerable participants who may find the interaction with peers empowering [26]. Separate sessions were held, one with the novice nurses and one with the expert nurses. Similar open ended questions guided both focus group discussions. The groups were facilitated by the same doctorally-prepared nurse who was experienced in focus group methodology and aware of the importance of encouraging dialogue between participants [26]. Three novice nurses and three expert nurses attended their respective focus group. At each focus group, open-ended interviews were audiotaped and the tapes were transcribed. The novice nurse focus group preceded the expert nurse focus group. This supported the facilitator's ability to probe the expert nurses in areas that the novice nurses had discussed, such as the suggestion to have a group based CS model rather 
than the novice/expert model. Approval to conduct the study was received from the hospital's research ethics board.

This study took place at a tertiary perinatal unit in a large, urban teaching centre where 4000 births take place annually. This setting was the workplace of two of the investigators. Participants included nursing staff from the Birthing Unit and the Mother-Baby Unit. New staff had completed a formal orientation process that consisted of ten to 12 weeks of clinical preceptoring and in-class learning. At the time of this study, there was no ongoing support for staff after the formal orientation ended.

The CS study used a constructivist analysis that led to the identification of patterns from the qualitative data collected in the two focus groups. In a constructivist analysis overall patterns emerge and are named as the data is examined, without prior selection of theoretical perspectives [27]. The two lead investigators reviewed the transcripts in hard copy word documents and completed the analysis, using colour coding. Initially the data for the novice nurses and expert nurses was analyzed separately. However, the early patterns from each of these two participant groups were directly related, and led to the researchers merging the findings. Three main study patterns emerged, incorporating data from both the novice nurses and expert nurses. Further analysis revealed three smaller themes in the first pattern. Initial study findings, both patterns and themes, were reviewed with the expert nurses to ensure face validity. Their feedback was incorporated into the ongoing analysis. The expert nurses confirmed the patterns and themes were valid from their perspective. The novice nurses were not involved in this validation process.

\section{STUDY FINDINGS}

During the constructivist data analysis three main patterns emerged: Readiness to Reflect, Valuing of Clinical Supervision, and Sustainability of Clinical Supervision. Three themes identified within the readiness to reflect pattern were timing, uncertainty and resistance. Separate themes were not identified in the other two patterns.

\subsection{Pattern One: Readiness to Reflect}

The response of novice nurses and expert nurses revealed a limited readiness to reflect on the part of the novice nurses. They reported being "surprised by the idea of clinical supervision". One stated, "I think we were kind of feeling why is this going to help us?" The expert nurses noted that the novice nurses weren't ready to reflect on their practice and wanted instead to focus on solidifying their clinical skills. As one expert nurse stated, "I didn't feel them [the novice nurses] necessarily hesitating to bring things up, but just genuinely didn’t really feel like they had a lot of difficult situations to bring up.”

Timing. Novice Nurses expected to be given time to prepare and to have meetings during scheduled shifts, rather than during additional paid hours, one stated, "[I] don't want to do nursing after hours." Although they were paid to attend meetings, they did not want to spend their personal time on CS. Expert nurses found it difficult to book meeting times with the novice nurses. Novice nurses needed to be approached several times before a meeting time could be confirmed. As one expert nurse stated, "There was a bit of avoidance".

Uncertainty. The novice nurses were uncertain about the intention of CS and were apprehensive about what to expect, “I don't know what you call it, worried, I guess", "...surprised at the idea of clinical supervision, concerned”, while another nurse felt uncertain and “...didn’t know how to prepare..."

Resistance. Resistance to engaging in the clinical supervision program was evident in the dialogue of the novice nurses. Novice nurses spoke in terms of involuntary relationships, "Seeing that we are going to be locked up together" and commented that meetings were difficult to organize, "It was difficult to get together". One novice nurse questioned the usefulness of the model of clinical supervision, "And I guess I came in there feeling like it wasn't all that useful because we sit there and talk about the same things we talk about all the time.” The novice nurses resisted engaging in an activity they didn't value and were expected to participate in. Expert nurses identified novice nurses' resistance and avoidance. Shift work and concerns regarding confidentiality were reasons cited for this resistance.

Expert nurses struggled to establish a relationship with the novice nurses. Novice nurses remained confused about the goal of clinical supervision, wondering why the expert nurses did not come to the practice setting to work with the novice nurses on their scheduled shifts. The novice nurses were focused on doing, while the clinical supervision model encouraged them to reflect upon their practice with an expert nurse outside of the clinical setting. Both the novice and expert nurses recognized that the novice nurses did not seem ready initially to engage in a reflective process such as clinical supervision.

\subsection{Pattern Two: Valuing of Clinical Supervision}

Valuing of Clinical Supervision had both positive and negative dimensions. Despite the challenges introducing clinical supervision in this setting, there were indications that both groups found some value in the relationships they developed. One novice nurse stated, "I just had a 
run-in with [someone] ....and we talked about that. My expert nurse also had an experience. It was nice that she had similar stories." Expert nurses identified that some novice nurses were having a hard time eliciting support on their units, and so having the opportunity to talk to the expert nurse was a valuable resource. One expert nurse stated, "I think it is valuable because I think that first year of a new grad can make or break their decision to stay in nursing." Two quotes from the expert nurses speak to the value of the CS program to facilitate the development of supportive relationships, "So in the later sessions I did find they were probably a little more confident in bringing those kinds of things forward" and "I have continued on with the people that we have hired and I find it's a great benefit."

However, there were questions from both groups regarding the value of clinical supervision. In the novice group, comments from two of the novice nurses included: "I didn't find that we really had enough clinical stuff to fill the whole time", "I felt like we were just chatting", "[I] didn't have much to talk about at meetings. One novice nurse stated, "I felt floored and confused because I didn't know what it was about so was interested in knowing how that would help me in my practice."

Overall, the valuing of clinical supervision by the novice nurses was low. Expert nurses felt that the novice nurses didn't see the purpose of the meetings and described that some were difficult to sit through because the novice nurse had nothing to discuss. Meetings felt uncomfortable, "I found my first session quite contrived". Expert nurses reported that initially trust was lacking, "It was just I remember there wasn't that trust there”, but once trust developed, novice nurses looked to the expert nurses for reassurance and clarification.

\subsection{Pattern Three: Sustainability of Clinical Supervision}

Novice nurses offered suggestions to foster the sustainability of the clinical supervision model. One novice nurse indicated she would like to see the expert nurse more often. Another talked about increasing choice regarding who would provide clinical supervision, "Choosing [a] preceptor works much better. Maybe [we could]... pick expert nurses for clinical supervision, not be assigned". Other suggestions included having the sessions begin earlier and take place more often.

Expert nurses suggested improvements in the approach to CS that could make future relationships sustainable. One expert nurse wondered if it would have been beneficial to have expert nurses who were colleagues in the unit rather than someone in an advance practice nurse role. Expert nurses and one novice nurse suggested a group approach to clinical supervision might be more effective. Both novice and expert nurses shared suggestions on how to improve the model of clinical supervision that addressed the challenges they had experienced.

\section{DISCUSSION}

The findings of this study highlight the experiences of novice and expert nurses participating in a program of clinical supervision at the end of their orientation to a perinatal unit. Valuing of clinical supervision was a dynamic pattern, with the expert nurses placing a higher value on the potential of clinical supervision while the novice nurses critiqued the reality of clinical supervision.

Novice nurses described a lack of readiness to participate, uncertainty and resistance. The expert nurses also identified these responses in the novice nurses. Elements in the design of a CS program, specifically timing, frequency of meetings, and choice of expert participants, if designed well, could better foster novice nurses' engagement. Expert nurses thought highly of the opportunity to offer this support to new staff, in contrast to the novice nurses who questioned its purpose. All participants made recommendations to improve implementation of the program in orderfor clinical supervision to continue. Our findings suggest that the novice and expert nurses recognized that clinical supervision needed to be tailored to meet the needs of the novice millennial nurses to increase overall engagement.

\section{IMPLICATIONS FOR PRACTICE AND RESEARCH}

The findings of this study lead to recommendations for other centres considering CS as a model of support for novice nursing staff. In retrospect, it is clear that specific elements of our model impacted how CS was received in our setting. The lack of clarity regarding the purpose of $\mathrm{CS}$, and the timing and frequency of meetings were barriers to the novice nurses' readiness to reflect and value clinical supervision.

Timing and frequency of meetings were also problematic. CS meetings were scheduled outside of work hours and novice nurses participating in this study were resistant to this. Other studies have also reported nurses' ambivalence about participating in programs of clinical supervision [21,23]. While clinical supervision sessions should occur often enough that the learners' needs are met, timing and frequency of meetings should be taken into consideration to support millennial nurses' values and assumptions about workplace culture and work-life balance. We recommend that timing of sessions should be built into the novice nurses' schedules so that there is not an expectation for them to participate outside of scheduled shifts.

Nurses participating in earlier CS studies did not make 
their participation a priority. Instead, they described using other approaches to receive emotional support from peers [20]. Similarly in this study, the novice nurses indicated that they created their own support system within the workplace. Yet, having only an informal support system is potentially problematic since reliance solely on informal peer discussions does not ensure reflection on practice or the development of responsibility for their own practice. Pairing novice nurses and experienced nurses who did not interact regularly was also a weakness in this design. Overcoming resistance would require engaging novice nurses in the development of a model that ensures timely feedback. Other authors have suggested a shift away from a novice/expert nurse dyads towards peer group-based clinical supervision $[4,21,28]$. This approach might have more appeal to millennial nurses and engage them more actively in reflection.

For centres considering CS as a way to support novice nurses, we encourage close attention be paid to the needs and expectations of millennial learners and suggest the term generational sensitivity, modeled after the accepted notion of cultural sensitivity, be used. Generational sensitivity regarding this group of novice nurses would include a model where the novice nurse selects the experienced nurse to work with, rather than being assigned an expert nurse, and small group cohort meetings rather than meeting one-on-one. Studies that reported positive outcomes related to the implementation of clinical supervision were designed with orientation sessions that were conducted away from the workplace and novice staff were given the option to select their own supervisor $[29,30]$. Novice nurses may not have felt at ease meeting with the expert nurses or may not have met often enough to establish a supportive relationship. There is growing evidence that providing support to new graduate nurses is valuable especially if that support is provided by experienced nurses close at hand [2,31].

Millennial novice nurses may purposefully seek out supports that are closer in experience to the novice nurse, rather than the expert nurses. If generation is an important motivator, novice nurses may choose an experienced nurse who is closer in age to them rather than the most expert nurse in the setting. Such a model may work effectively if the experienced nurses have timely access to the support of the expert nurses. A CS model where experienced nurses support reflective practice in new graduates, while expert nurses then support experienced nurses, may be more effective. While CS was well supported in this study in terms of budget and staffing, this was not enough to ensure the program's success. We recommend modification to the design of this model of support based on our learning and evaluation prior to full implantation in other settings.
We also recommend further evaluation of clinical supervision in settings where the modifications suggested for practice have been implemented.

\section{STRENGTHS AND LIMITATIONS}

While Clinical Supervision is well integrated into professional practice in the United Kingdom, this is the first time CS has been evaluated in Canada or in a perinatal setting. This study included a small sample size and findings cannot be generalized but may be of value to settings who have similar models of clinical supervision.

\section{CONCLUSION}

There is now a body of literature describing the challenges and difficulties that new graduate nurses experience $[1,2,32]$. This study highlights some challenges when clinical supervision was introduced in a Canadian perinatal setting. Recommendations for developing a program of clinical supervision for novice nurses include using experienced colleagues rather than expert nurses, ensuring that the timing of sessions is immediate and during scheduled working hours, and giving novice nurses the opportunity to identify a experienced nurse in their practice setting, rather than having one assigned. An informal, flexible approach to new nursing graduates, based on generational sensitivity, is suggested to provide the support needed to engage novice nurses and promote reflection in the first year of professional practice.

\section{REFERENCES}

[1] Edwards, D., Burnard, P., Hannigan, B., Cooper, L., Adams, J., Juggessur, T., Fothergill, A. and Coyle, D. (2006) Clinical supervision and burnout: The influence of clinical supervision for community health nurses. Journal of Clinical Nursing, 15, 1007-1015. doi:10.1111/j.1365-2702.2006.01370.x

[2] Rhéaume, A., Clement, L., LeBel, N. and Robichaud, K. (2011) Workplace experiences of new graduate nurses. Canadian Journal of Nursing Leadership, 24, 80-98.

[3] Cho, S.-H., Lee, L.Y., Mark, B.A. and Yun, S.-C. (2012) Turnover of new graduate nurses in their first job using survival analysis. Journal of Nursing Scholarship, 44, 6370. doi:10.1111/j.1547-5069.2011.01428.x

[4] Duchscher, J.E.B. and Cowin, L. (2004) The experience of marginalization in new nursing graduates. Nursing Outlook, 52, 289-296. doi:10.1016/j.outlook.2004.06.007

[5] Weston, M. (2006) Integrating generational perspectives in nursing. OJIN: The Online Journal of Issues in Nursing, 11, Manuscript 1.

http://www.nursingworld.org/MainMenuCategories/ANA Marketplace/ANAPeriodicals/OJIN/TableofContents/Vol ume112006/No2May06/tpc30_116073.aspx 
[6] Sujansky, J. (2004) Leading a multi-generational workforce. Occupational Health \& Safety, 73, 16-18. http://search.proquest.com/docview/221000173?accounti $\mathrm{d}=47688$

[7] Duchscher, J.E.B. and Cowin, L. (2004) Multigenerational nurses in the workplace. Journal of Nursing Administration, 34, 493-501. doi:10.1097/00005110-200411000-00005

[8] Cole, G., Lucas, L. and Smith, R. (2002) The debut of Generation Y in the American workforce. Journal of Business Administration, 1, 1-10.

[9] Alch, M. (2000) Get ready for the net generation. Training \& Development, 54, 32-34.

[10] Kramer, M. (1974) Reality shock: Why nurses leave nursing. American Journal of Nursing, 75, 891. doi:10.1097/00000446-197505000-00041

[11] Department of Health (1993) A vision for the future: The nursing, midwifery and health visiting contribution to health and health care. NHS Management Executive: Stationery Office, London.

[12] Butterworth, T. (1995) Clinical supervision in nursing, midwifery and health visiting: Development, contracts, and monitoring. The University of Manchester, Manchester, 1-2.

http://www.nursing.manchester.ac.uk/research/officialrep orts/ClinicalSupervision2.pdf

[13] Butterworth, T., Carson, J., White, E., Jeacock, J., Clements, A. and Bishop, V. (1997) It is Good to talk: An evaluation of clinical supervision and mentorship in England and Scotland. University of Manchester, Manchester.

[14] Butterworth, T., Bell, L., Jackson, C. and Pajnkihar, M. (2008) Wicked spell or magic bullet? A review of the clinical supervision literature 2001-2007. Nurse Education Today, 28, 264-272. doi:10.1016/j.nedt.2007.05.004

[15] Bedward, J. and Daniels, H.R.J. (2005) Collaborative solutions: Clinical supervision and teacher support teams reducing professional isolation through effective peer support. Learning in Health and Social Care, 4, 53-66. doi:10.1111/j.1473-6861.2005.00090.x

[16] Hyrkas, K. and Punonwn-Ilmonen, M. (2001) The effects of clinical supervision on the quality of care: Examining the results of team supervision. Journal of Advanced Nursing, 33, 492-502. doi.org/10.1046/j.1365-2648.2001.01685.X

[17] Jones, A. (2001) Some experiences of professional practice and beneficial changes derived from clinical supervision by community MacMillan Nurses. European Journal of Cancer Care, 10, 21-30. doi:10.1046/j.1365-2354.2001.00209.x

[18] Marrow, C.E., Holyoake, K., Hamer, D. and Kenrick, C. (2002) Clinical supervision using video conferencing technology: A reflective account. Journal of Nursing Management, 10, 275-282. doi:10.1046/j.1365-2834.2002.00313.x

[19] Teasdale, K., Brocklehurst, N. and Thom, N. (2001) Clinical supervision and support for nurses: An evaluation study. Nursing and Health Care Management, 33,

\section{6-224. doi:10.1046/i.1365-2648.2001.01656.x}

[20] Haggman-Laitila, A., Eriksson, E., Ritta, M., Kirsi, S. and Leena, R. (2007) Nursing students in clinical practiceDeveloping a model for clinical supervision. Nursing Education in Practice, 7, 381-391. doi:10.1016/j.nepr.2006.11.011

[21] Buus, N.S., Angel, M., Traynor, M. and Gonge, H. (2011) Psychiatric nursing staff members' reflections on participating in group-based clinical supervision: A semistructured interview study. International Journal of Mental Health Nursing, 20, 95-101. doi:10.1111/j.1447-0349.2010.00709.x

[22] Cottrell, S. (2002) Suspicion, resistance, tokenism and mutiny: Problematic dynamics relevant to the implementation of clinical supervision in nursing. Journal of Psychiatric and Mental Health Nursing, 9, 667-671. doi:10.1046/j.1365-2850.2002.00517.x

[23] Jones, A. (2006) Clinical supervision: What do we know and what do we need to know? A review and commentary. Journal of Nursing Management, 14, 577-585. doi:10.1111/j.1365-2934.2006.00716.x

[24] Lynch, L. and Happell, B. (2008) Implementation of clinical supervision in action: Part 2: Implementation and beyond. International Journal of Mental Health Nursing, 17, 65-72. doi:10.1111/j.1447-0349.2007.00512.x

[25] Lynch, L. and Happell, B. (2008) Implementation of clinical supervision in action: Part 3: The development of a model. International Journal of Mental Health Nursing, 17, 73-82. doi:10.1111/j.1447-0349.2007.00513.x

[26] Ivanoff, S.D. and Hultburg, J. (2006) Understanding the multiple realities of everyday life: Basic assumptions in focus-group methodology. Scandinavian Journal of Occupational Therapy, 13, 125-132. doi:10.1080/11038120600691082

[27] Lincoln, Y.S. (1990) The making of a constructivist: A remembrance of transformations past. In Guba, E.G., Ed., The Paradigm Dialog, SAGE Publications, Newbury Park, 67-87.

[28] Lakeman, R. and Glasgow, C. (2009) Introducing peergroup clinical supervision: An action research report. International Journal of Mental Health Nursing, 18, 204210. doi:10.1111/j.1447-0349.2009.00602.x

[29] Edwards, D., Cooper, L., Burnard, P., Hanningan, B., Adams, B.J., Fothergill, A. and Coyle, D. (2005) Factors influencing the effectiveness of clinical supervision. Journal of Psychiatric and Mental Health Nursing, 12, 405414. doi:10.1111/j.1365-2850.2005.00851.x

[30] Whitestanley, J. and White, E. (2003) Clinical supervision: Models, measures and best Practice. Nurse Researcher, 10, 7-37.

[31] Benner, P., Sutphen, M., Leonard, V. and Day, L. (2010) Educating nurses: A call for radical transformation. JosseyBass, San Francisco.

[32] Maddalena, V., Kearney, A.J. and Adams, L. (2012) Quality of life of novice nurses. Journal for Nurses in Staff Development, 28, 74-79. doi:10.1097/NND.0b013e31824b41a1 